\title{
Zhong-Yong as dynamic balancing between Yin-Yang opposites
}

\author{
Xin $\mathrm{Li}$ \\ Copenhagen Business School, Copenhagen, Denmark
}

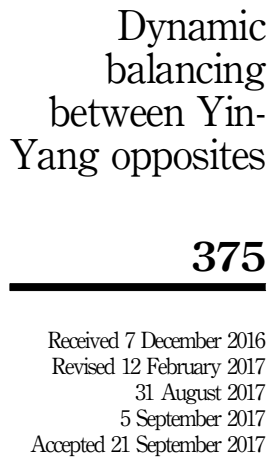

\begin{abstract}
Purpose - The purpose of this paper is to comment on Peter Ping Li's understanding of Zhong-Yong balancing, presented in his article titled "Global implications of the indigenous epistemological system from the East: How to apply Yin-Yang balancing to paradox management." Seeing his understanding of Zhong-Yong balancing being incorrect and incomplete, the author proposes an alternative perspective on Zhong-Yong as dynamic balancing between Yin-Yang opposites.

Design/methodology/approach - The author first explain why Peter P. Li's "asymmetry" and "superiority" arguments are flawed by referring to the original text of the classical book of Zhong-Yong (中庸) and a comparison between Zhong-Yong and Aristotle's doctrine of the mean. The author then propose an alternative approach to Zhong-Yong balancing that is embedded in the original text Zhong-Yong but somehow has been neglected by many Chinese scholars. The author concludes the commentary by unifying the two alternative approaches to Zhong-Yong balancing under the inclusion-selection-promotion-transition (ISPT) framework of Zhong-Yong balancing.

Findings - There are three main findings. First, as the original text of Zhong-Yong does not prescribe asymmetry, Peter P. Li's notion of "Yin-Yang balancing" is ironically unbalanced or anti-Zhong-Yong due to his emphasis on asymmetry to the exclusion of symmetry. Second, due to the equivalency between Zhong-Yong and Aristotle's doctrine of the mean, Peter P. Li's assertion that "Yin-Yang balancing" is superior as a solution to paradox management is flawed. Third, his "Yin-Yang balancing" solution is only (the less sophisticated) one of two alternative approaches to Zhong-Yong balancing, i.e., ratio-based combination of Yin-Yang opposites. What Peter P. Li and many other Chinese have neglected is another approach to Zhong-Yong that is embedded in the original text of Zhong-Yong, which I call "analysis plus synthesis."

Research limitations/implications - As it is a commentary there are no specific limitations except for what can be covered in the space available.

Practical implications - The "analysis plus synthesis" approach to Zhong-Yong can be adopted by practitioners who are demanded to balance between opposite forces in daily life and work.

Social implications - The rejection of the "Yin-Yang balancing being superior" assertion facilitates reduction of friction and non-cooperation between intellectual traditions.

Originality/value - This commentary contributes to the "West meets East" discourse by debunking Peter P. Li's assertion that Yin-Yang balancing is superior as a solution to paradox management and his prescription that balancing between Yin-Yang opposites must be asymmetric. It also contributes to the Chinese indigenous management research by identifying a largely neglected approach to Zhong-Yong balancing (i.e. "analysis plus synthesis") that is alternative to the commonly understood ratio-based combination approach (e.g. "Yin-Yang balancing"). In addition, it contributes to the management literature by proposing the ISPT framework of Zhong-Yong balancing.
\end{abstract}

Keywords Symmetry, Asymmetry, Balancing, Yin-Yang, Doctrine of the mean, Zhong-Yong

Paper type Viewpoint

In the first issue of Cross Cultural and Strategic Management after the journal's official rebranding, Li (2016) presents a viewpoint titled "Global implications of the indigenous epistemological system from the East: How to apply Yin-Yang balancing to paradox management." What he means by "Yin-Yang balancing" is essentially the Confucian notion of

(C) Xin Li. Published by Emerald Publishing Limited. This article is published under the Creative Commons Attribution (CC BY 4.0) licence. Anyone may reproduce, distribute, translate and create derivative works of this article (for both commercial and non-commercial purposes), subject to full attribution to the original publication and authors. The full terms of this licence may be seen at http://creativecommons.org/licences/by/4.0/legalcode

The author is grateful to the anonymous reviewer and Professor Rosalie Tung, the Editor-in-Chief of Cross Cultural and Strategic Management, for their comments and suggestions. All errors remain the author's.

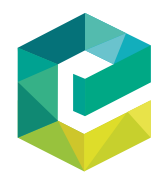

Cross Cultural \& Strategic Management
Vol. 25 No. 2, 2018 pp. 375-379 
CCSM

25,2

Zhong-Yong (中庸) although he avoids using the term because Zhong-Yong is precisely about dynamic balancing between Yin-Yang opposites.

While his analysis has some merits, it has two fundamental flaws. The first is his prescription of "asymmetrical balancing," namely, "Yin-Yang balancing" "require[s] one of the two opposite elements to play the dominant role [...] while the other opposite element will play the subordinate role" (Li, 2016, p. 57, italic added). The second is his assertion of the superiority of "Yin-Yang balancing" as a solution to paradox management, namely, among all "five cognitive or logical systems [that] can be extracted [...] Yin-Yang balancing is the only one that fully embraces paradox" (Li, 2016, p. 58, italic added).

My commentary aims to explain why the aforementioned "asymmetry" and "superiority" arguments are flawed on the one hand, and to present an alternative understanding of Zhong-Yong on the other.

Take the asymmetry argument first. Elsewhere, Peter P. Li puts it a categorical statement that "opposite elements [...] must adopt an asymmetrical pattern" (Lin et al., 2015, p. 334, italic added). However, in the original text of Zhong-Yong, one of the four Confucian classical books, there is no such an asymmetry prescription. On the contrary, in chapter ten of Zhong-Yong, there is a sentence “故君子和而不流; 中立而不倚,” which can be translated as "Thus the respectable men maintain harmony but do not simply follow others without thinking; they stand in the middle without leaning to either side." This sentence justifies symmetry as a legitimate pattern in Zhong-Yong balancing.

In fact, both symmetric and asymmetric balances are legitimate. In chapter two of Zhong-Yong, there is a sentence “君子之中庸也, 君子而时中,” which can be translated as "The respectable men practice Zhong-Yong and they do so according to the specific situations they are in." This notion of “时中” (situational Zhong-Yong) gives flexibility to the practice of Zhong-Yong balancing, namely, one may choose symmetric or asymmetric balance according to the specific situation facing him or her, on the one hand; and one should dynamically adjusts the pattern (switching between symmetry and asymmetry, or altering the degree of asymmetry) in response to the change of the situation facing him or her, on the other hand.

Peter P. Li recognizes that "the interaction and inter-transformation of opposite elements tend to trigger a dynamic shift in the relative status or positions of opposite elements from a dominant to a subordinate role, or vice versa" (Li, 2016, p. 57). Obviously, the shift from one type of asymmetry (e.g. yin being dominant and yang being subordinate) to the opposite type of asymmetry (i.e. yin being subordinate and yang being dominant) must go through the phase of symmetry (i.e. yin and yang being equal). This also means, Zhong-Yong balancing allows both symmetry and asymmetry.

Yet, in order to be consistent with his asymmetry prescription, Peter P. Li argues that "a swift switch in the relative status between dominant and subordinate roles is often desirable" (Li, 2016, p. 58, italics added). However, the sharp contrast between the failures of the "shock therapy" reforms implemented in the former Soviet Union economies in 1990s and the success of the gradualist reform approach adopted by China since 1980s clearly contradicts Peter P. Li's argument (Blanchard and Kremer, 1997; Qian et al., 1999). The "shock therapy" reform prescribes a swift switch between two opposite models of economy, i.e., a socialist economy with the state sector as the dominant and the private sector the subordinate vis-à-vis a capitalist economy with the private sector as the dominant and the state sector the subordinate. In contrast, China's gradualist economic transition allowed a slow change of the relative weight of the state sector vis-à-vis the private sector in the Chinese economy.

In addition, the emphasis on asymmetry to the exclusion of symmetry in balancing Yin-Yang opposites may have negative consequences. In the Chinese culture, yin is associated with female while yang male. The exclusive emphasis on asymmetry might be used to justify gender inequality, as men (yang) were treated as being superior to women (yin) in the imperial China. When it comes to the discourse of "West meets East," although Peter P. Li (2012, p. 90, 
italics added) once talked about "the emerging trend for the West to meet and integrate with the East on an equal footing toward a balanced geocentric meta-paradigm," he has recently come to stress "the possibility for an East-West integration as an asymmetrical balance with perhaps more emphasis on the Eastern philosophy" (Li, 2016, p. 44, italics added).

Peter P. Li's "Yin-Yang balancing" approach to paradox management can be summarized by four "partial's, namely, epistemologically, the two opposites in a paradox should be seen as being partially conflicting and partially complementary, and methodologically, the two opposites should be partially separated and partially integrated. On the operational level, the essence of "Yin-Yang balancing" is to include two opposites in the final solution with a "properly balanced ratio" between the two (Li, 2014, p. 330; Lin et al., 2015; cf. March, 2010, p. 81). Simply speaking, "Yin-Yang balancing" results in a compromised solution, $n$ percent of which is consisted of the yin element and the rest 100- $n$ percent of the yang element (see Figure 1). For example, a "Yin-Yang balancing" solution to March's (1991) exploration-exploitation paradox is not to fully focus on either exploration or exploitation but to allocate part of firm resources for exploration and part for exploitation (Li et al., 2012).

However, such a ratio-based approach to balancing is entirely compatible with Aristotle's Doctrine of the Mean as outlined in his Nicomachean Ethics. According to Gottlieb (2009, p. 19), Aristotle's Doctrine of the Mean has three aspects: "First, virtue, like health, is in equilibrium and is produced and preserved by avoiding extremes and hitting the mean; it is self-sustaining. Second, virtue is in a mean "relative to us." Third, each virtue is in a mean between two vices, one of excess and one of deficiency." So, Aristotle's mean is not an arithmetic calculation equidistant from two opposed extremes. The mean is "relative to us," which "cannot be determined without close attention to features of the persons to whom such means are relative and the circumstances in which those persons are placed" (Losin, 1987, p. 332). Such a mean "relative to us" is equivalent to the Confucian notion of “时中" (situational Zhong-Yong), i.e., balancing according to the specific circumstances of the situation.

The equivalency between Zhong-Yong and Aristotle's doctrine of the mean implies that Chinese and Westerners may come up with similar or equivalent solutions to paradox management. As a matter of fact, without resorting to Yin-Yang or Zhong-Yong, Nagji and Tuff (2012) have provided a solution to the exploration-exploitation paradox that has close resemblance to the "Yin-Yang balancing" solution. Namely, they found successful firms normally simultaneously invest in three categories of activities, i.e., core (exploiting existing), adjacent (expanding from existing core into "new to the company" business), and transformational (exploring breakthroughs and things new to the market). They found, on average, high-performing firms allocate about 70 percent of their resources to enhance existing core businesses, 20 percent to exploit adjacent opportunities, and 10 percent to explore transformational initiatives. Therefore, there appears to be no basis in asserting the superiority of "Yin-Yang balancing."

Ratio-based combination

$n \%$ : Yin $+(100-n) \%$ : Yang $=$ compromized Zhong-Yong solution

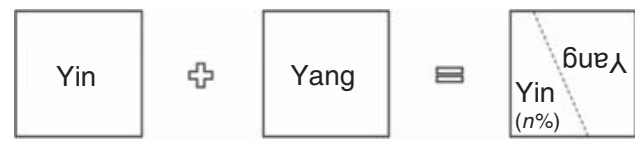

"Analysis plus synthesis"

Parts of Yin + parts of Yang=composite Zhong-Yong solution

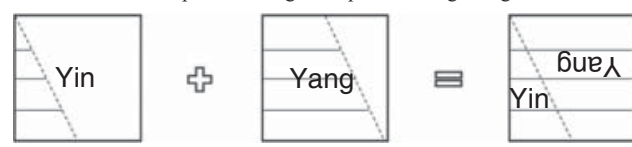

Figure 1.

Two alternative approaches to Zhong-Yong balancing 
CCSM

25,2

378

In my view, Peter P. Li's understanding of Zhong-Yong (in the name of "Yin-Yang balancing") is not only incorrect (i.e. emphasizing asymmetry to the exclusion of symmetry) but also incomplete. To be fair, his ratio-based approach to Zhong-Yong is a very common understanding of Zhong-Yong shared by many Chinese. However, what Peter P. Li and many other Chinese have neglected is another approach to Zhong-Yong that is more sophisticated than the ratio-based one.

This largely neglected approach is embedded in chapter six of Zhong-Yong, i.e., “舜其大 知也与. 舜好问而好察迩言, 隐恶而扬善, 执其两端, 用其中于民. 其斯以为舜乎.” This sentence can be translated as "the sage-king Shun indeed was greatly wise! Shun loved to ask people and study their words though they might be shallow. He discarded the bad parts in them and promoted the good parts. He took hold of extremes and chose something in between them to be used in his government of the people. It was by this that he was Shun." Shun's approach to balancing between opposite opinions is not to compromise by mixing $n$ percent of one extreme opinion and $100-n$ percent of another extreme, but to analyze what are the good and bad parts in each of the two opposite opinions and then combine the good parts while discarding the bad parts of both opposite opinions.

I use the phrase of "analysis plus synthesis" to generalize Shun's approach into a generic solution to Zhong-Yong balancing. Here, "analysis" means, when managing paradoxical opposites, one should avoid treating each opposite as an unbreakable unitary entity because doing so leads one to treat each opposite as a "black box" without deep understanding of it; instead, one should try to open up the "black box" by analyzing its inner structure and mechanism. For example, in managing the exploration-exploitation paradox, one should try to understand what exploration/exploitation really is: for example, what activities are involved, how the activities are structured or connected, how many critical phases are there in the process of exploration/exploitation, etc. With such an analysis or understanding, one is in a better position to balance exploration and exploitation by synthesizing or integrating parts of both opposites in a creative way, resulting in a composite solution (see Figure 1).

This "analysis plus synthesis" approach to Zhong-Yong also has equivalent in Western thinking, e.g., embodied in the phrase "get the best of both worlds." Stroh and Miller (1994) identify "best of both" thinking" as one of four generic approaches to manage paradox. Without resorting to Yin-Yang or Zhong-Yong, Gulati and Garino (2000) offer a solution to balancing the traditional (bricks) and e-commerce (clicks) business models that has close resemblance to the "analysis plus synthesis" approach. They do not treat the traditional business and e-commerce models as "black boxes," but dissect them into several aspects, i.e., brand, top management team, operations, and equity ownership, and then show different companies have adopted different degrees of integration of the two business models on these different aspects.

The two alternative approaches to Zhong-Yong balancing, i.e., ratio-based combination and "analysis plus synthesis," can be both operationalized by the inclusion-selection-promotiontransition framework, first proposed by Xin Li (2014). Here, inclusion means when balancing opposites, one should always include both opposites. For the ratio-based combination approach, inclusion means both opposites are treated as unbreakable unitary entities and included in the final solution with a "properly balanced ratio" between the two. For the "analysis plus synthesis" approach, inclusion means elements or parts of both opposites are included in the final solution. Selection means something is to be selected or treated as priority. For the ratio-based combination approach, selection means one of the two opposites as a whole should be selected as priority or play a dominant role while the other subordinate in Peter P. Li's words. For the "analysis plus synthesis" approach, selection means some elements or parts of each opposite should be selected as priority while other elements or parts are un- or under-prioritized. Promotion means, while one should prioritize something, he or she should also promote the other un- or under-prioritized to prevent the potential crowding out of them by the prioritized. For the ratio-based combination approach, promotion means to increase the relative importance 
of the subordinate role when the change of situation requires one to do so. For the "analysis plus synthesis" approach, promotion means to increase the relative value of the un- or underprioritized parts or elements of each opposite. Transition means, as time passes, the external as well as internal environments or circumstances may have changed, the prioritization choice should also be altered, and therefore one should deliberately transit from the current prioritization to a new prioritization. For the ratio-based combination approach, the transition is between the two opposites each of which is taken as a whole in terms of which one plays the dominant role and which the subordinate. For the "analysis plus synthesis" approach, the transition is between the prioritized and un- or under-prioritized parts or elements of each opposite in terms of which is to be selected as priority.

\section{References}

Blanchard, O. and Kremer, M. (1997), "Disorganization”, Quarterly Journal of Economics, Vol. 112 No. 4, pp. 1091-1126.

Gottlieb, P. (2009), The Virtue of Aristotle's Ethics, Cambridge University Press, Cambridge.

Gulati, R. and Garino, J. (2000), "Get the right mix of bricks \& clicks", Harvard Business Review, Vol. 78 No. 3, pp. 107-114.

Li, P.P. (2012), "Exploring the unique roles of trust and play in private creativity: from the complexityambiguity-metaphor link to the trust-play-creativity link", Journal of Trust Research, Vol. 2 No. 1, pp. 71-97.

Li, P.P. (2014), "The unique value of Yin-Yang balancing: a critical response", Management and Organization Review, Vol. 10 No. 2, pp. 321-332.

Li, P.P. (2016), "Global implications of the indigenous epistemological system from the East: how to apply Yin-Yang balancing to paradox management", Cross Cultural \& Strategic Management, Vol. 23 No. 1, pp. $42-77$.

Li, P.P., Li, Y. and Liu, H. (2012), "The exploration-exploitation link reframed from paradox into duality”, working paper, Asia Research Center, Copenhagen Business School, Frederiksberg.

Li, X. (2014), "The hidden secrets of the Yin-Yang symbol”, Copenhagen Discussion Papers No. 46, Asia Research Centre, Copenhagen Business School, Frederiksberg.

Lin, D., Lu, J., Li, P.P. and Liu, X. (2015), "Balancing formality and informality in business exchanges as a duality: a comparative case study of returnee and local entrepreneurs in China", Management and Organization Review, Vol. 11 No. 2, pp. 315-342.

Losin, P. (1987), “Aristotle's doctrine of the mean”, History of Philosophy Quarterly, Vol. 4 No. 3, pp. 329-341.

March, J.G. (1991), "Exploration and exploitation in organizational learning”, Organization Science, Vol. 2 No. 1, pp. 71-87.

March, J.G. (2010), The Ambiguities of Experience, Cornell University Press, Ithaca, NY.

Nagji, B. and Tuff, G. (2012), "Managing your innovation portfolio", Harvard Business Review, Vol. 90 No. 5 , pp. 66-74.

Qian, Y., Roland, G. and Xu, C. (1999), "Why is China different from Eastern Europe? Perspectives from organization theory”, European Economic Review, Vol. 43 No. 4, pp. 1085-1094.

Stroh, P. and Miller, W.W. (1994), "Learning to thrive on paradox", Training \& Development, Vol. 48 No. 9, pp. 28-39.

\section{Corresponding author}

Xin Li can be contacted at: xl.int@cbs.dk

For instructions on how to order reprints of this article, please visit our website:

www.emeraldgrouppublishing.com/licensing/reprints.htm

Or contact us for further details: permissions@emeraldinsight.com

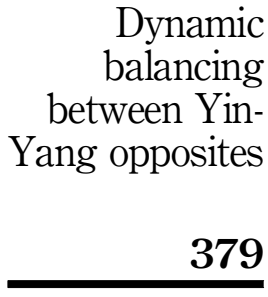

Dynamic balancing between YinYang opposites 